Original article

\title{
Chronic viral HBeAg-negative hepatitis B: Epidemiological, clinical and biochemical characteristics in an outpatient descriptive cohort in Burkina Faso
}

\author{
Eric Nagaonlé Somé ${ }^{\mathrm{a}, *}$, Alice Nanelin Guingané ${ }^{\mathrm{b}}$, Issaka Zongo ${ }^{\mathrm{a}}$, Daouda Sané ${ }^{\mathrm{b}}$, \\ Koiné Maxime Drabo ${ }^{a}$, Roger Sombié ${ }^{b}$ \\ ${ }^{a}$ Institut de Recherche en Sciences de La Santé (IRSS) Ouagadougou, Burkina Faso \\ ${ }^{\mathrm{b}}$ Gastro-enterology Department, UFR/SdS, Université Joseph Ki-Zerbo, Ouagadougou, Burkina Faso
}

\section{A R T I C L E I N F O}

\section{Keywords:}

Viral hepatitis

Hepatitis B virus

Hepatitis B e Antigen

Sub saharan Africa

\begin{abstract}
A B S T R A C T
Introduction: Our study aimed to describe epidemiological and diagnostic features in an outpatient's cohort with chronic HBeAg-negative hepatitis B.

Patients and methods: A cross-sectional descriptive study with a retrospective data collection was implemented from January 2004 to April 2016 in the hepato-gastroenterology department of the University Teaching Hospital Yalgado Ouédraogo (CHU-YO) in Burkina Faso.

Results: Overall $325 \mathrm{HBeAg}$ negative patients met the inclusion criteria. The sex ratio was 1.5 and the mean age 38.7 years. The most frequent circumstance of diagnosis was the health check-up (54.5\%). The mean HBsAg concentration and viral load were $7861.6 \mathrm{IU} / \mathrm{mL}$ and $32237.20 \mathrm{IU} / \mathrm{mL}$, respectively. Low or moderate inflammatory activity was found in $44 \%$ and $24 \%$ of patients, respectively at the liver biopsy; $32 \%$ presented a portal fibrosis with some septa (F2). $43.9 \%$ and $41.6 \%$ had low (A1) or moderate (A2) inflammatory activity, respectively at the hepatic fibrosis blood test, while $59.1 \%$ and $20.4 \%$ had low (F1) or moderate (F2) fibrosis stage, respectively. Of the five biochemical and virological profiles among the untreated patients, the profile 1 represented $67.2 \%$ of the sample.

Conclusion: The proportions of negative HBeAg in chronic hepatitis B patients are increasing in Burkina Faso. Most of the patients have a high viral load, a low to moderate inflammatory activity or fibrosis stage.
\end{abstract}

\section{Introduction}

Five types of agents including viruses A, B, C, D and E are involved in viral hepatitis. ${ }^{1,2}$ More serious than hepatitis A, better known than hepatitis $\mathrm{C}$ or $\mathrm{E}$, more frequent than hepatitis $\mathrm{D}$ which is only a very inconsistant co-infection or superinfection, hepatitis B appears to be the most important disease in the viral hepatitis series. Viral hepatitis $\mathrm{B}$ (VHB) is an inflammatory disease of the liver caused by the hepatitis B virus (HBV). It constitutes a major public health problem both in terms of its seriousness and its evolution towards chronicity, as well as the number of affected subjects and the diversity of its clinical forms. The World Health Organization (WHO) ${ }^{3}$ estimated that two billion people including ten to thirty million infections per year, would be infected during their life-course. Also according to WHO in 2015, around 257 million people suffered from chronic hepatitis B worldwide with a high frequency in African countries and more than 800,000 people died from it.

In Burkina Faso, the prevalence of $\mathrm{HBs}$ antigen ( $\mathrm{HBsAg}$ ) is estimated at $9.1 \% .{ }^{4}$ The HBV transmission is predominantly vertical (mother-tochild) or horizontal (sexual and other close contact). ${ }^{5}$ Despite the existence of an effective vaccine recommended by WHO, the number of patients chronically infected with the hepatitis B virus is still important in Sub Saharan Africa. In this area, the infection is often acquired at birth leading easily to the chronic carriage because of the immune-tolerance. ${ }^{5,6}$ Following the immune-tolerance phase the immune reactivation with a negativation of the $\mathrm{HBeAg}$ with or without appearance of anti-HBe antibodies $(\mathrm{Ab})$ corresponds to the infection control phase. However, due to a pre-C/C mutation, HBeAg may no longer be secreted despite the presence of antiHBeAb. This situation has become very frequent $(87 \%$ in Europe and $50-80 \%$ in Asia and the Mediterranean

\footnotetext{
* Corresponding author. 10 BP 250 Ouagadougou 10, Burkina Faso.

E-mail address: eric.some@gmail.com (E.N. Somé).
} 
zone). ${ }^{6,7}$

In Burkina Faso, Sombié ${ }^{8}$ in 2010 found a proportion of $77.7 \%$ for chronic hepatitis B HBeAg-negative patients. This form is at risk of a long-term progression toward serious fibrosis, cirrhosis or hepatocellular carcinoma (HCC). It should prompt a discussion on an antiviral treatment initiation with the objective to obtain a HBs seroconversion. ${ }^{9}$ The gastro-enterology department of the university teaching hospital Yalgado Ouédraogo follows up a cohort of thousands of chronic hepatitis B patients. Still in Burkina Faso, little is known regarding the clinical and biological profile of the HBeAg-negative patients. Describing the profile and specific features of HBeAg-negative patients may improve the patients' monitoring while allowing a customization of the provided care. Our study aimed to describe the epidemiological and clinical features in an outpatient's cohort with chronic HBeAg-negative hepatitis B.

\section{Patients and methods}

\section{Study type and duration}

A cross-sectional descriptive study with a retrospective data collection was implemented from January 2004 to April 2016.

\section{Data source, sampling and sample size}

Our study took place at the hepato-gastroenterology department of the University Teaching Hospital Yalgado Ouédraogo (CHU-YO) in Burkina Faso. The patients were selected from a larger outpatients' cohort. We included patients aged at least 15 years, with positive $\mathrm{HBsAg}$ for more than six months and a negative $\mathrm{HBeAg}$ and whose latest laboratory tests including the alanine-amino-transferease (ALT) and/or the HBV DNA, were $\leq$ one year. Patients with decompensated cirrhosis or primary liver cancer were excluded. The sample size included 325 patients.

\section{The study overview}

A monthly, then quarterly and semi-annual monitoring of the ALT was carried out. Serum creatinine and serum phosphorus were performed every six months in patients taking treatment. A lab analysis for HBsAg, HBeAg and HBV-DNA was performed every six months or one year. HBsAg was detected by the Determine ${ }^{\mathrm{TM}}$ technique (Abbott) and Elisa (Vidas ${ }^{\circledR}$ ). The HBsAg was quantified using $\mathrm{HBs}$ Ag II quant II Cobas: $0.05 \mathrm{IU} / \mathrm{mL}$ to $52,000 \mathrm{IU} / \mathrm{mL}(\log 10: 2.11)$. Quantification of HBV-DNA was performed by real-time PCR (Roche Cobas Taq Man, sensitivity threshold $20 \mathrm{IU} / \mathrm{mL}$ ). An ultrasound and/or abdominal CT scan were performed annually in the absence of cirrhosis and every six months otherwise. Liver activity and fibrosis were assessed by a liver biopsy or a liver fibrosis blood test (FibroMeter ${ }^{\circledR}$ ). Antiviral therapy was indicated in patients with a liver activity and/or fibrosis $\geq 2$. In the context of an increase in ALT greater than twice the upper limit of the normal range in a patient with a detectable viral load, treatment was started regardless of the status of hepatic fibrosis. The complete virological response was defined as undetectable HBV -DNA obtained within one year of treatment.

\section{Data management and statistical analysis}

Data were collected using a data collection form. The relevant variables included socio-demographic, clinical, biological and virological characteristics. We implemented basic descriptive univariate analysis on the relevant variables, displaying means and proportions. The treatment compliance was assessed over the last three months by a visual analogue scale (VAS) from 0 to 10 (0: no treatment taken at all, to 10: no treatment skipped). Three adherence groups were defined including a high adherence group (HAG where no dose was missed, mean VAS score of 10 over the last four weeks), moderate adherence group (MAG: overall compliance over the last 4 weeks between mean VAS score 8.1 to 9.9) and the low adherence group (LAG with a mean VAS score $\leq 8$ over the last four weeks). The data were analysed with Epi Info 7 software.

Ethics

This study was implemented in the context of a medical doctorate thesis. The data collecting forms were anonymised. The study obtained the required authorizations from the hospital management team. It was a retrospective collection of routine data of the gastro-enterology department.

\section{Operational definitions}

We categorized five biochemical and virological profiles:

- first profile: HBV-DNA < $2000 \mathrm{IU} / \mathrm{ml}$ and ALT still within the normal range (inactive carriage);

- second profile: a high HBV-DNA > 20,000 IU/ml and ALT consistently above the normal range;

- third profile: a fluctuating viral replication and ALT values without any normalization window;

- fourth profile: a succession of periods of elevated ALT followed by spontaneous normalization and a fluctuating viral replication;

- fifth profile: the immune-tolerance phase with an HBV-DNA > 20,000 $\mathrm{IU} / \mathrm{ml}$ and ALT consistently within the normal range.

\section{Study results}

From January 2004 to April 2016, we recruited 1133 patients with chronic viral hepatitis B. Overall 325 (28.7\%) patients were $\mathrm{HBeAg}$ negative and met the inclusion criteria.

\section{Sociodemographic and clinical characteristics}

Our study population consisted of $60 \%$ of men, meaning a sex ratio of 1.5 (Table 1 . The mean age was 38.7 years. The youngest patient was 16 and the oldest 74 . The $25-44$ year-old age group represented $67 \%$ of the patients. Employees in the formal public or private sector, were the most represented with $197(60.6 \%)$ of the patients. Married participants represented $61.8 \%$. In terms of lifestyle, occasional alcohol consumption was found in $134(41.2 \%)$ patients and 17 (5.2\%) patients were

Table 1

Basic socio-demographic characteristic.

\begin{tabular}{lll}
\hline Basic socio-demographic characteristics & Frequency & Percent (\%) \\
\hline Gender & & \\
Male & 195 & 60 \\
Age group & 19 & 5.8 \\
16-24 & 101 & 31.1 \\
$25-34$ & 117 & 36.0 \\
35-44 & 63 & 19.4 \\
45-54 & 25 & 7.7 \\
$\geq 55$ & & \\
Employment & 62 & 19.1 \\
Pupils/Students & 197 & 60.6 \\
Formal sector & 66 & 20.3 \\
Informal sector & & \\
Marital status: & 210 & 61.8 \\
married & & \\
Lifestyle & 134 & 41.2 \\
Alcohol consumption & 17 & 5.2 \\
Smoking & 174 & 53.6 \\
No alcohol no smoking & & \\
Family history: & 53 & 16.3 \\
HBsAg + or HCC & & 54.5 \\
Circumtance of diagnosis & 177 & 33.5 \\
Health checkup & 109 & 4.9 \\
Blood donation & 16 & \\
Antenatal visit & 23 & \\
Diagnostic & & \\
\hline & &
\end{tabular}


smoking. A family history of HBsAg carriage or primary liver cancer was found in $53(16.3 \%)$ patients.

The most frequent circumstance of diagnosis in our series was the health check-up (54.5\%). The health check-up can be broken-up in the health check-up per se, but also prenuptial health check-ups, hepatitis B screening campaigns and family screening around a newly diagnosed HBsAg-positive patient, the annual occupational medical check-up and finally the HBV pre-vaccination assessment. The second circumstance of discovery was the blood donation (33.5\% of the participants). The physical examination was normal in 319 (98.2\%) patients and suggestive of cirrhosis in the others.

\section{Biochemical and virological tests}

The mean HBsAg concentration from 188 (57.8\%) patients was $7861.6 \mathrm{IU} / \mathrm{mL}$ (range from $2 \mathrm{IU} / \mathrm{mL}$ to $\geq 52,000 \mathrm{IU} / \mathrm{mL}$ ). The mean viral load (from all participants) was $32237.20 \mathrm{IU} / \mathrm{mL}$ (range: 0 to 91086 $744 \mathrm{IU} / \mathrm{mL}$ ). HBV DNA was detectable (greater than 20IU/ml) in 258 patients (79.4\%). ALT concentration was controlled every month for six months in 241 untreated patients and was normal in $78 \%$ of them. Table 2 indicates the distribution of patients according to the ALT changes.

HBV serology was positive in 19/121 tested partners and $17.5 \%$ of the $\mathrm{HBsAg}$ negative spouses received the hepatitis B vaccination. $\mathrm{HBsAg}$ was also tested positive in $5 / 109$ children and $23.1 \%$ of the HBsAg negative children were also immunized against HBV. The viral hepatitis $\mathrm{C}$ and D tests were positive in $4 / 310$ and $1 / 184$ patients respectively, while the HIV test was positive in $3 / 305$ participants.

We observed the five biochemical and virological profiles among the untreated patient population (Fig. 2). The profile 1 represented $67.2 \%$ of the sample. The mean age of these inactive carriers was 38 (range: 16 to 63) years. Patients with profile 5 had a mean age of 39.4 (ranges: 27; 52) years.

\section{Ultrasound, endoscopy and biopsy investigations}

The Abdominal ultrasound was normal in 276 (84.9\%) patients. The results are summarized in Fig. 1.

Thirteen patients performed the digestive endoscopy which found two cases of a grade II esophageal varices (15.4\%) and one case of bulbar ulcer, acute gastritis, esophageal mycosis and congestive antritis, respectively. The liver biopsy from 25 patients (Table 3) showed low or moderate inflammatory activity in $44 \%$ and $24 \%$ of patients, respectively, and a portal fibrosis with some septa (F2) (32\%). A total of 132 (40.6\%) patients performed the hepatic fibrosis blood test (Table 3); $43.9 \%$ and $41.6 \%$ had low (A1) or moderate (A2) inflammatory activity, respectively while $59.1 \%$ and $20.4 \%$ had low (F1) or moderate (F2) fibrosis stage, respectively.

\section{Discussion}

\section{Socio-demographic and professional characteristics}

The sex-ratio was 1.5 . This male predominance was reported by many authors ${ }^{10,11}$ and clearly indicated that VHB became chronic more often in men than in women. The mean age of our patients was 38.7 years. Usually, patients in resource-limited settings are younger than those in developed countries, as transmission is predominantly perinatal in LMICs.

Table 2

Distribution of patients according to the transaminases (ALAT) changes.

\begin{tabular}{lll}
\hline Transaminases (ALT) & Frequency & Percent (\%) \\
\hline Normal & 188 & 78 \\
Abnormal with fluctuation & 42 & 17.4 \\
Consistently abnormal & 11 & 4.6 \\
TOTAL & $\mathbf{2 4 1}$ & $\mathbf{1 0 0}$ \\
\hline
\end{tabular}

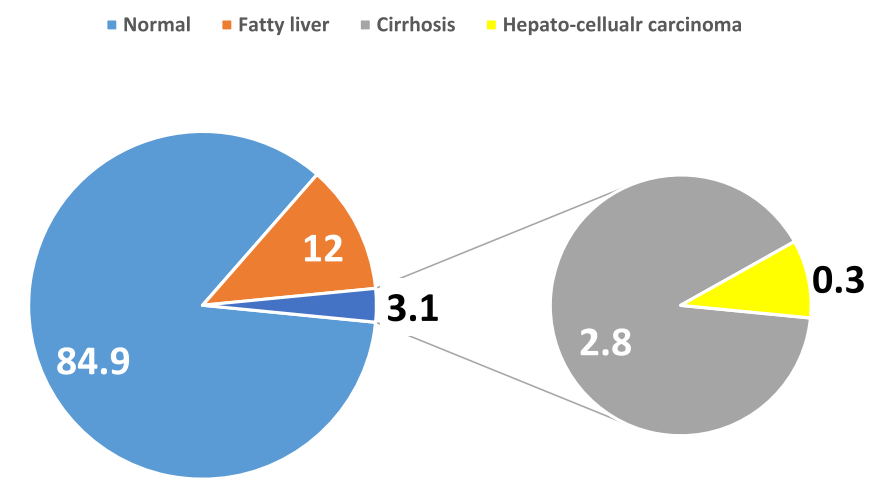

Fig. 1. Distribution of patients according to ultrasound results.

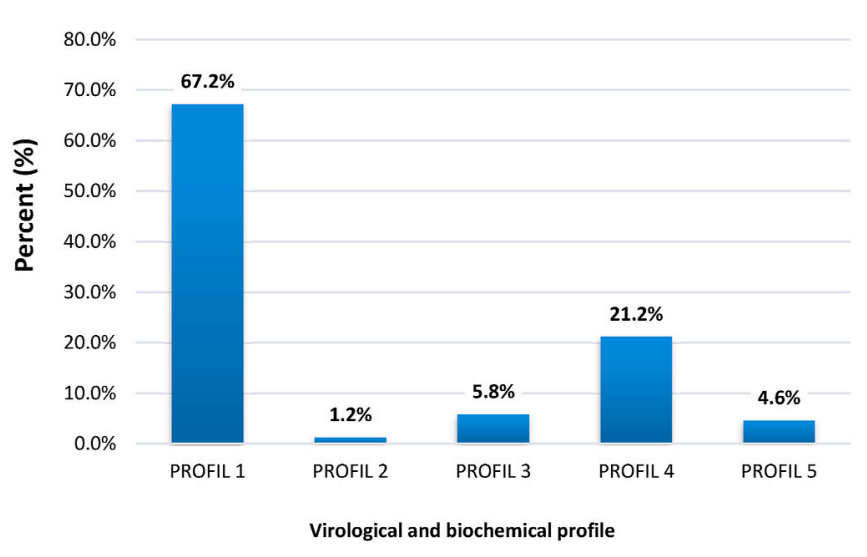

Fig. 2. Distribution of untreated patients according to virological and biochemical profile.

Table 3

Distribution of patients according to the grade of inflammatory activity and the stage of fibrosis of the METAVIR score $(n=25)$ assessed by the histology and the fibrometer.

\begin{tabular}{lll}
\hline Results & Frequency & Percent (\%) \\
\hline Histology $(\mathrm{n}=25)$ & & \\
Activity grade & 3 & 12 \\
A0 & 11 & 44 \\
A1 & 6 & 24 \\
A2 & 5 & 20 \\
A3 & & \\
Fibrosis stage & 4 & 16 \\
F0 & 8 & 32 \\
F1 & 8 & 32 \\
F2 & 4 & 16 \\
F3 & 1 & 4 \\
F4 & & \\
Fibrometer $\left.{ }^{(n}=132\right)$ & & \\
Activity grade & 13 & 9.8 \\
A0 & 58 & 43.9 \\
A1 & 55 & 41.6 \\
A2 & 6 & 4.5 \\
A3 & & \\
Fibrosis stage & 10 & 7.6 \\
F0 & 78 & 59.1 \\
F1 & 27 & 20.4 \\
F2 & 12 & 9.1 \\
F3 & 5 & 3.8 \\
F4 & & \\
\hline
\end{tabular}

Our study population consisted mainly of employees of the formal sector (public or private). This category of population generally benefits from an annual occupational health check-up and also constitutes a target audience for blood collection operations. It is also more educated, 
therefore better informed and has more financial capacity to meet the demands of regular monitoring.

Occasional alcohol consumption was noted in $41.2 \%$ of patients. This result was comparable to Ganesan's ${ }^{12}$ in the United States and even Kabore (unpublished thesis) in Burkina Faso, who found respectively $50 \%$ and $34 \%$ of alcohol consumption in their study populations. Alcohol is a risk factor in the progression of the fibrosis when consumption topped at more than $50 \mathrm{~g}$ per day. The fibrosis observed in $\mathrm{HBV}$ infection is worsen by the alcohol consumption. ${ }^{13,14}$ Alcohol is the $1^{\text {st }}$ cause of the hepatocellular carcinoma in Western countries, before the HBV infection. In Sub Saharan Africa, alcohol is less involved in hepatitis, even if it is recognized as an accelerating factor in the liver degeneration by viral infection aetiologies. ${ }^{15,16}$ In our study, HBV testing was performed by the majority during a health check-up. The increasing awareness raised by $\mathrm{WHO}$, in relation to the objectives to control hepatitis by $2030^{3}$ might explain this preventive screening.

\section{Clinical and paraclinical characteristics}

\section{Hepatitis B screening and viral load}

Overall, $121(37.2 \%)$ partners and 109 (33.5\%) children of the HBsAg-positive patients were also screened for HBV. This finding showed that the family screening is not common in Burkina Faso and raised the issue of the efficacy of the HBsAg-positive patients'follow-up to prevent other horizontal transmission within the family. The very low proportion of immunized people among HBsAg-negative family members put a particular emphasis on this issue.

The HBV viral load was detectable in $79.4 \%$ of patients. This result indicated an ongoing viral replication in patients carrying anti-HBeAb despite the absence of $\mathrm{HBeAg}$. In the literature authors showed that most HBeAg negative patients who had an ongoing viral replication while carrying anti- $\mathrm{HBeAb}$ were infected with a viral strain with a G1896A-mutation in the pre-core region. ${ }^{7,17}$ This mutation leads to the generation of a stopping codon preventing the HBeAg synthesis while viral replication remains possible. A detectable viral load means an ongoing viral replication which will result in the onset of the hepatic activity and then hepatic fibrosis. This activity and fibrosis could in turn progress to cirrhosis and then hepatocellular carcinoma.

\section{Co-infection}

The prevalence of HBV-HIV co-infection was $0.9 \%$ in our study. This prevalence is lower than the findings elsewhere which were from $10 \%$ to up to $25 \% .^{18,19}$ The HBV-HIV co-infection rate in Burkina Faso was similar to the national HIV prevalence which was $0.92 \%$ according to the UNAIDS 2015 report. Therefore, HBV infected people has similar risk than the general population to acquire HIV infection. In the literature, the HBV-HIV co-infection rate fluctuates between 5 and $7 \%$ in low-endemicity countries for hepatitis B and $10-20 \%$ in intermediate to high endemicity countries. The modes of transmission of HIV and HBV are common and $50-80 \%$ of patients infected with HIV have at least one serological marker for $\mathrm{HBV} .^{20}$

The hepatitis D test was positive in one patient. The HDV and HBV transmission modes are comparable and HDV can only infect HBsAg positive subjects. The HDV infection can occur in two ways: an HBVHDV co-infection (simultaneous infection with both viruses) or a superinfection of an HBV chronic infection by the HDV. The HBV-HDV coinfection induces a high risk of fulminant hepatitis. Actually, the superinfection by the delta virus of a chronic hepatitis B patient or an HBsAg carrier is characterized by more severe liver damages, a more rapid progression to cirrhosis and a high risk of developing a hepatocellular carcinoma. ${ }^{21}$; therefore, the HDV screening should be systematically performed in any patient infected with hepatitis B.

Four $(1.2 \%)$ patients had a positive result for anti-HCVAb testing. The presence of anti-HCVAb does not necessarily imply chronic hepatitis $\mathrm{C}$; the analysis of viral RNA is necessary to confirm the diagnosis. In the literature, HBV-HCV co-infection is associated with more severe histological lesions (high risk of malignant degeneration), and an inhibition of the HBV replication. The majority of HBV-HCV co-infected patients have a detectable level of HCV RNA and an undetectable or low level of HBV DNA, which means that the hepatitis $C$ virus is predominant and it is responsible for liver damage in these patients. ${ }^{22,23}$

\section{Virological and biochemical profile}

In our study, inactive HBV carriers represented $67.2 \%$ of untreated patients. Bennajma in Morocco and $\mathrm{Sia}^{24}$ reported a rate of $59 \%$ and $22.98 \%$ respectively of inactive HBV carriers. No case of reactivation was diagnosed. The prognosis for this profile is usually very good and long-term follow-up studies demonstrated that the disease most often remains inactive. The risk of HCC is seldom. ${ }^{25}$ In other studies, a low risk of viral reactivation (annual incidence of less than 1.1\%) has been observed in inactive HBV carriers who had an HBsAg concentration $<1000 \mathrm{IU} / \mathrm{mL}$. $^{25}$ The quantifications of HBsAg and the viral load are essential monitoring tools for HBV patients. ${ }^{26}$ Liver biopsy is seldom implemented because it is scary for the patients. The blood test using the FibroMeter is preferred, although it remains very expensive for the economic context ( $\$ 125 /$ analysis). The liver biopsy was performed for $25(7.7 \%)$ patients. Although invasive the liver biopsy remains the "gold standard" for assessing the degree of the liver activity and fibrosis. There is a poor correlation between serum transaminasis activity and the degree of liver damage, especially in patients with chronic HBeAg negative hepatitis. The liver biopsy is therefore recommended before starting antiviral B treatment. However, the FibroMeter ${ }^{\circledR}$ is in practice a better alternative for safety reasons and it can be used in follow-up to assess the stage of the fibrosis. ${ }^{27}$

\section{Limitations of the study}

A significant number of patients lacked biological and ultrasound monitoring data. Financial reason seemed to be behind this, as the study was designed to analyse routine data. We therefore believe that the description given in this work did not present the whole reality of our cohort. However, what was observed in this work gave us a fairly objective picture of the evolution of an HBsAg-positive HBeAg-negative patient regularly monitored.

\section{Conclusion}

The proportions of negative $\mathrm{HBeAg}$ in chronic hepatitis B patients are increasing sharply in Burkina Faso. Most of the patients have a high viral load, a low to moderate inflammatory activity or fibrosis stage. Sensitizing the population about the modes of transmission and generalizing the HBV screening and vaccination still remain the strongest weapons to control the HBV infection. A particular emphasis should be placed in Burkina Faso on family screening when a case is diagnosed in the family.

\section{Source of funding}

This research did not receive any specific grant from funding agencies in the public, commercial, or not-for-profit sectors.

\section{CRediT authorship contribution statement}

Eric Nagaonlé Somé: Data curation, Writing - original draft, Writing - review \& editing. Alice Nanelin Guingané: Writing - original draft, Writing - review \& editing. Issaka Zongo: Writing - review \& editing. Daouda Sané: Methodology, Investigation, Investigation, Formal analysis, Data curation, Data Curation. Koiné Maxime Drabo: Writing - review \& editing. Roger Sombié: Conceptualization, Methodology, Supervision, Project administration, Writing - review \& editing. 


\section{Declaration of competing interest}

None.

\section{Acknowledgement}

We are much grateful to the staff of the gastro-enterology department who contributed greatly to and facilitated the data collection. We want also to thank the administration of the university teaching hospital Yalgado Ouedraogo who provided all permission to make possible the data collection.

\section{References}

$1 \mathrm{Xu}$ R, Gan X, Fang Y, Zheng S, Dong Q. A simple, rapid, and sensitive integrated protein microarray for simultaneous detection of multiple antigens and antibodies of five human hepatitis viruses (HBV, HCV, HDV, HEV, and HGV). Anal Biochem. 2007; 362(1):69-75.

2 Sugitani M, Sheikh A, Suzuki K, et al. Sero-epidemiology of sporadic acute hepatitis in Bangladesh: high prevalences of infection with type-B, type-E and multiple types of hepatitis virus. Ann Trop Med Parasitol. 2009;103(4):343-350.

3 World Health Organization. Global Hepatitis Report. vol. 83. Geneva: Global Hepatitis Programme; 2017. World Health Organization.

4 Meda N, Tuaillon E, Kania D, et al. Hepatitis B and C virus seroprevalence, Burkina Faso: a cross-sectional study. Bull World Health Organ. 2018;96(11):750-759.

5 Umar M, Hamama Tul B, Umar S, Khan HA. HBV perinatal transmission. Int J Hepatol. 2013:875791.

6 Lee HA, Lee HW, Kim IH, et al. Extremely low risk of hepatocellular carcinoma development in patients with chronic hepatitis B in immune-tolerant phase. Aliment Pharmacol Ther. 2020;52(1):196-204.

7 Kheirabad AK, Farshidfar G, Nasrollaheian S, Gouklani H. Prevalence and characteristics of precore mutation in Iran and its correlation with genotypes of hepatitis B. Electron Physician. 2017;9(4):4114-4123.

8 Sombié R, Bougouma A, Diallo O, et al. Hépatite B chronique: aspects épidémiologique, diagnostique, thérapeutique et évolutif au centre hospitalier universitaire Yalgado Ouédraogo de Ouagadougou. Journal Africain d'HépatoGastroentérologie. 2010;4(1):3-10.

9 Lee HW, Kim SU, Baatarkhuu O, et al. Progression of untreated minimally active chronic HBV infection compared to inactive infection. Clin Gastroenterol Hepatol. 2019;17(13):2808-28010 e2.
10 Kpossou A, Paraiso M, Sokpon C, et al. Hépatite virale B lors d'une campagne de dépistage en population générale au Bénin: séroprévalence et facteurs associés. PAMJ. 2020;37(247):1-12.

11 Wongjarupong N, Yonli AT, Nagalo BM, et al. Characteristics of patients with chronic hepatitis B virus infection with genotype E predominance in Burkina Faso. Hepatol Commun. 2020;4(12):1781-1792.

12 Ganesan M, Eikenberry A, Poluektova L, Kharbanda K, Na O. Role of alcohol in pathogenesis of hepatitis B virus infection. World J Gastroenterol. 2020;26(9).

13 Jaquet A, Tchounga B, Tanon A, et al. Etiology of hepatocellular carcinoma in West Africa, a case-control study. Int J Canc J Int Canc. 2018;143(4):869-877.

14 Jaquet A, Wandeler G, Nouaman M, et al. Alcohol use, viral hepatitis and liver fibrosis among HIV-positive persons in West Africa: a cross-sectional study. J Int AIDS Soc. 2017;20:21424.

15 Vento S, Dzudzor B, Cainelli F, Tachi K. Liver cirrhosis in sub-Saharan Africa: neglected, yet important. Lancet Glob Health. 2018;6(10):e1060-e1061.

16 Pimpin L, Cortez-Pinto H, Negro F, et al. Burden of liver disease in Europe: epidemiology and analysis of risk factors to identify prevention policies. $J$ Hepatol. 2018;69(3):718-735.

17 Wang XL, Ren JP, Wang XO, Wang XH, Yang SF, Xiong Y. Mutations in pre-core and basic core promoter regions of hepatitis B virus in chronic hepatitis B patients. World J Gastroenterol. 2016;22(11):3268-3274.

18 Singh KP, Crane M, Audsley J, Avihingsanon A, Sasadeusz J, Lewin SR. HIV-hepatitis B virus coinfection: epidemiology, pathogenesis, and treatment. AIDS. 2017;31(15): 2035-2052.

19 Kim HN. Chronic hepatitis B and HIV coinfection: a continuing challenge in the era of antiretroviral therapy. Curr Hepatol Rep. 2020;19(4):345-353.

20 Leoni MC, Ustianowski A, Faroog H, Arends JE. HIV, HCV and HBV: a review of parallels and differences. Infect Dis Ther. 2018;7(4):407-419.

21 Koh C, Da BL, Glenn JS. HBV/HDV coinfection: a challenge for therapeutics. Clin Liver Dis. 2019;23(3):557-572.

22 Mavilia MG, Wu GY. HBV-HCV coinfection: viral interactions, management, and viral reactivation. J Clin Transl Hepatol. 2018;6(3):296-305.

23 Shih YF, Liu CJ. Hepatitis C virus and hepatitis B virus Co-infection. Viruses. 2020;12 (7).

24 Sia R. Les hépatites virales chroniques au Centre hospitalier Universitaire Yalgado Ouédraogo : aspects épidémiologiques, diagnostiques, thérapeutiques et évolutifs. Ouagadougou (PA): Univ de Ouagadougou; 2009:1-77 [Thèse].

25 Zarski JP, Marcellin P, Leroy V, et al. Characteristics of patients with chronic hepatitis B in France: predominant frequency of HBe antigen negative cases. $J$ Hepatol. 2006;45(3):355-360.

26 Cornberg M, Wong VW, Locarnini S, Brunetto M, Janssen HLA, Chan HL. The role of quantitative hepatitis B surface antigen revisited. J Hepatol. 2017;66(2):398-411.

27 Calès P, Boursier J, Oberti F, et al. FibroMeters: a family of blood tests for liver fibrosis. Gastrontérol Clin Bio. 2008;32:40-51. 